\title{
Brief review: Piriformis syndrome: etiology, diagnosis, and management
}

\section{Article de synthèse court: Le syndrome du muscle piriforme - étiologie, diagnostic et prise en charge}

\author{
Danilo Jankovic, MD • Philip Peng, MBBS • \\ André van Zundert, MD, PhD
}

Received: 27 May 2013/ Accepted: 15 July 2013/Published online: 27 July 2013

(C) Canadian Anesthesiologists' Society 2013

\begin{abstract}
Purpose In this narrative review, we aim to provide the pathophysiology and diagnostic criteria of the piriformis syndrome (PS), an underdiagnosed cause of buttock and leg pain that can be difficult to treat. Based on existing evidence, frequencies of clinical features are estimated in patients reported to have PS. In view of the increasing popularity of ultrasound for intervention, the ultrasoundguided technique in the treatment of PS is described in detail.

Source A literature search of the MEDLINE ${ }^{\circledR}$ database was performed from January 1980 to December 2012 using the search terms e.g., " piriformis injection", " ultrasound guided piriformis injection", " botulinum toxin", "pain management", and different structures relevant in this review. There was no restriction on language.
\end{abstract}

Author contributions Danilo Jankovic, Philip Peng, and André van Zundert contributed equally to the design, acquisition of data, drafting, and critical revision of the article.

\section{Jankovic, MD $(\bowtie)$}

Regional Pain Management Center DGS, Luxemburger Strasse 323-325, 50354 Cologne-Huerth, Germany

e-mail: danilo@jankovic1.de

P. Peng, MBBS

Department of Anesthesia, Toronto Western Hospital, University Health Network, University of Toronto, Toronto, ON, Canada

A. van Zundert, $\mathrm{MD}, \mathrm{PhD}$

Department of Anesthesiology, ICU \& Pain Therapy, Catharina Hospital-Brabant Medical School, Eindhoven, The Netherlands

A. van Zundert, $\mathrm{MD}, \mathrm{PhD}$

University of Ghent, Ghent, Belgium

A. van Zundert, $\mathrm{MD}, \mathrm{PhD}$

University of Maastricht, Maastricht, The Netherlands
Principal findings A review of the medical literature pertaining to PS revealed that the existence of this entity remains controversial. There is no definitive proof of its existence despite reported series with large numbers of patients.

Conclusion Piriformis syndrome continues to be a controversial diagnosis for sciatic pain. Electrophysiological testing and nerve blocks play important roles when the diagnosis is uncertain. Injection of local anesthetics, steroids, and botulinum toxin into the piriformis muscle can serve both diagnostic and therapeutic purposes. An ultrasound-guided injection technique offers improved accuracy in locating the piriformis muscle. Optimizing the therapeutic approach requires an interdisciplinary evaluation of treatment.

\section{Résumé}

Objectif Dans ce compte-rendu narratif, notre objectif est de présenter la physiopathologie et les critères diagnostiques du syndrome du muscle piriforme (SMP), une cause sous-diagnostiquée de douleurs aux fesses et aux jambes qui peut être difficile à traiter. En nous fondant sur les données probantes existantes, les fréquences des caractéristiques cliniques sont estimées chez des patients chez lesquels un SMP a été rapporté. Au vu de la popularité croissante de l'échographie pour assister les interventions, la technique échoguidée pour le traitement du SMP est décrite en détail.

Source Une recherche de littérature dans la base de données MEDLINE ${ }^{\circledR}$ a été réalisée couvrant la période allant de janvier 1980 à décembre 2012 avec les termes de recherche suivants, par exemple: "piriformis injection" (injection dans le piriforme), "ultrasound guided piriformis injection"(injection échoguidée dans le piriforme), " botulinum toxin " (toxine botulique), " pain management " (prise en charge de la douleur), ainsi que différentes 
structures pertinentes à ce compte-rendu. Aucune restriction de langue n'a été appliquée à la recherche.

Constatations principales Un examen de la littérature médicale concernant le SMP a révélé que l'existence d'un tel syndrome demeure controversée. Il n'existe pas de preuve absolue de son existence, malgré des séries de cas rapportées comportant un nombre élevé de patients.

Conclusion Le syndrome du muscle piriforme demeure un diagnostic controversé de douleur sciatique. Les tests électrophysiologiques et les blocs nerveux jouent des rôles importants lorsque le diagnostic est incertain. L'injection d'anesthésiques locaux, de corticostérö̈des, et de toxine botulique dans le muscle piriforme peut servir à des fins diagnostiques aussi bien que thérapeutiques. Une technique d'injection échoguidée permet de gagner en précision lors de la localisation du muscle piriforme. L'optimisation de l'approche thérapeutique nécessite une évaluation interdisciplinaire du traitement.

In this narrative review, we aim to provide a brief update regarding the pathophysiology and diagnostic criteria of the piriformis syndrome (PS), an underdiagnosed cause of buttock and leg pain that can be difficult to treat. Based on existing evidence, frequencies of clinical features are estimated in patients reported to have PS. In view of the increasing popularity of ultrasound for intervention, the ultrasoundguided technique in the treatment of PS is described in detail.

Piriformis syndrome is caused by prolonged or excessive contraction of the piriformis muscle (PM). Because of the close proximity to the sciatic nerve, PS is associated with pain in the buttocks, hips, and lower limbs. ${ }^{1-10}$ Yeoman (1928) was the first to describe pain in the sciatic distribution to PS. ${ }^{11}$ Beginning with Mixter and Barr's classic article (1934), ${ }^{12}$ the cause of sciatica and buttock pain was increasingly attributed to the lumbar spine. With a few exceptions, the literature on PS includes only isolated case reports. ${ }^{13-16}$ Many synonyms for the condition are used in the literature, such as "deep gluteal syndrome" and "pelvic outlet syndrome". ${ }^{17}$ Analogous to other entrapment neuropathies, such as carpal tunnel syndrome, this clinical picture can also be correctly termed "infrapiriform foramen syndrome". 18

It has been suggested that PS is responsible for 5-6\% of cases of sciatica. ${ }^{6,18-20}$ Taking a conservative estimate of new cases of low back pain and sciatica at 40 million annually, ${ }^{\mathrm{A}}$ the incidence of PS would be 2.4 million per

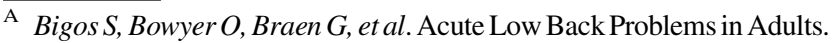
Rockville, MD: Agency for Health Care Policy and Research, Public Health Service, U.S. Department of Health and Human Services, 1994. (Clinical Practice Guideline No. 14. AHCPR Publication No. 95-0642.)
}

year. ${ }^{\mathrm{A}, 21}$ In the majority of cases, PS occurs in middle-aged patients (mean age $38 \mathrm{yr}$ ). ${ }^{22}$ The ratio of female to male patients with PS has been reported as $6: 1 .^{4}$

\section{Anatomy}

The PM is the only muscle that courses transversely through the greater sciatic notch, and it is the key landmark to all the important nerves and vessels that pass from the pelvis to the gluteal region (Figs. 1, 3A).

The innervation of the PM is usually derived from the first and second sacral nerves. There are six routes by which portions of the sciatic nerve may exit the pelvis, and these are illustrated in Fig. 2A-F.,13,23-28

\section{Pathophysiology and etiology}

There are two components contributing to the clinical presentation, namely, somatic and neuropathic. The somatic component underlying PS is a myofascial pain syndrome of the PM..$^{2,7,14,29,30}$ The symptomatology of the PS can also be contributed from a few muscles in the

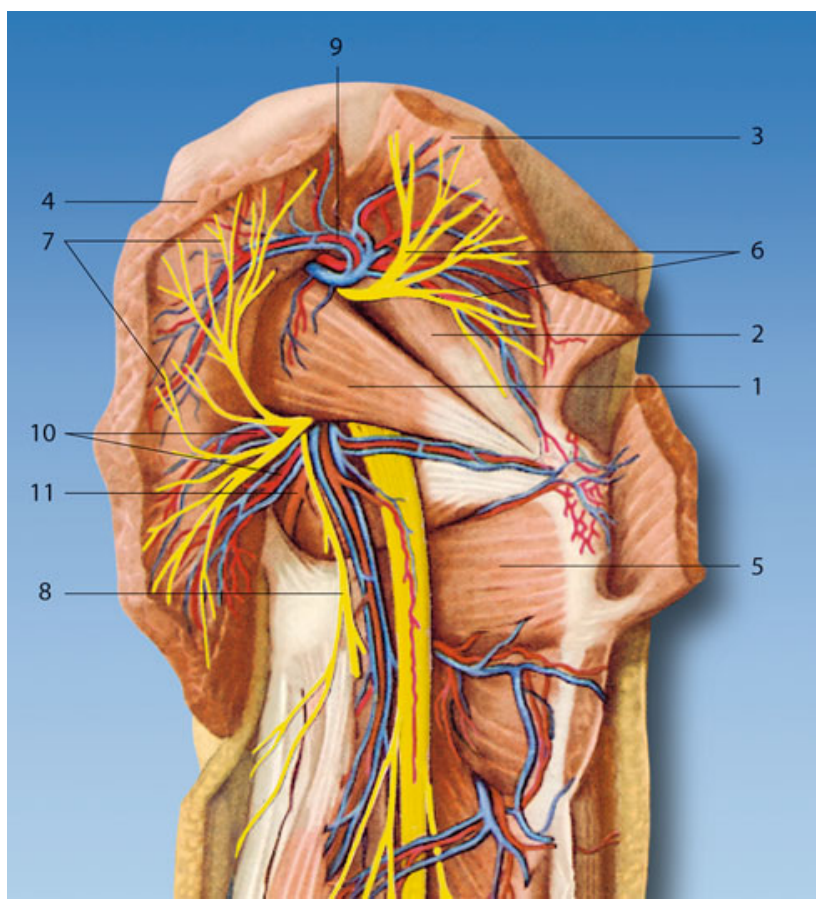

Fig. 1 The piriformis muscle (1) and neighboring muscles, nerves, and vessels: 2, gluteus minimus; 3, gluteus medius; 4, gluteus maximus; 5 , quadratus femoris; 6 , superior gluteal nerve; 7 , inferior gluteal nerve; 8 , posterior cutaneous femoral nerve; 9 , superior gluteal artery; 10, inferior gluteal artery and vein; 11, internal pudendal artery $^{91}$ (reproduced with permission from Danilo Jankovic.) 
A
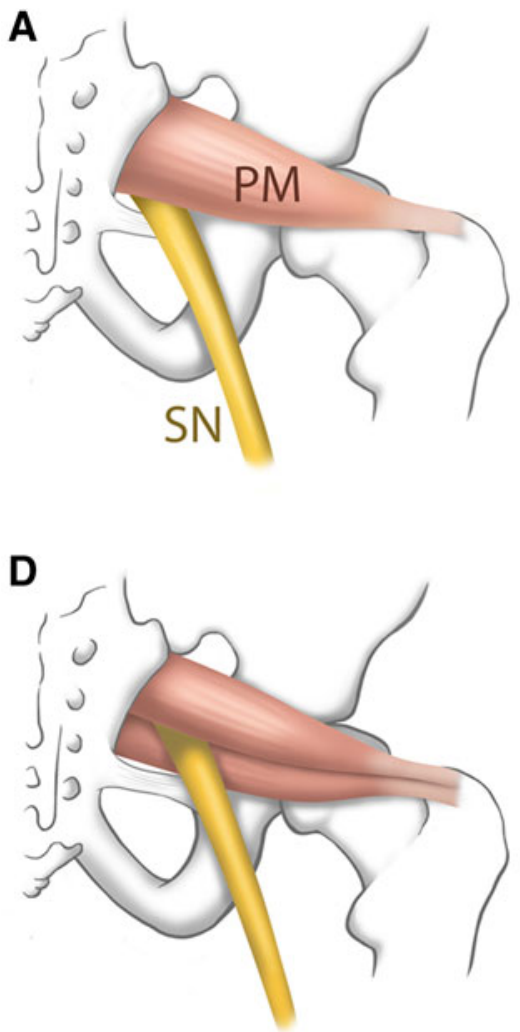
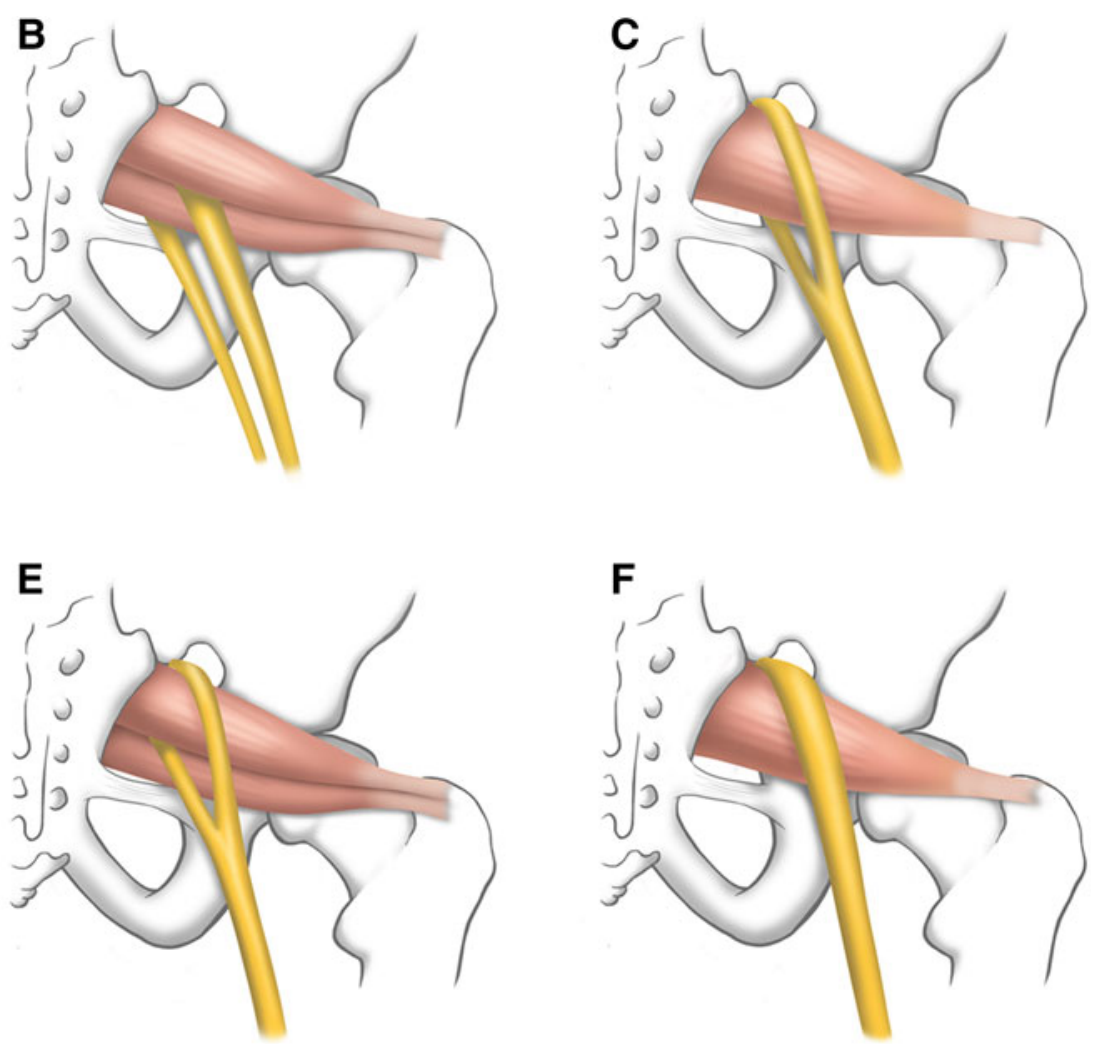

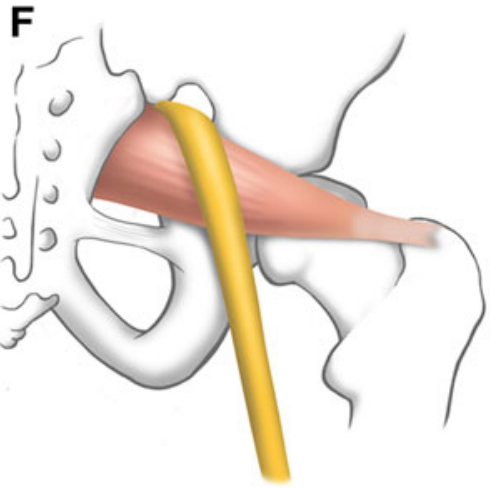

Fig. 2 The six routes by which portions of the sciatic nerve may exit the pelvis. ${ }^{28}$ (Reproduced with permission from Philip Peng Educational series.)

vicinity. They are the small external rotators of the hip (obturator internus, in particular, because it is partly an intrapelvic muscle and partly a hip muscle $)^{7,31}$ and the hamstring muscles (through activation and perpetuation of trigger points). ${ }^{7,32}$ The neuropathic component refers to the compression or irritation of the sciatic nerve as it courses through the infrapiriform foramen. ${ }^{5,9,14,20,33-37}$ In addition, irritation and compression of the neighbouring nerves and vessels (Figs. 1, 3A, 3D) can give rise to pain with a classic distribution pattern. ${ }^{7}$

A number of etiological factors that may account for the presence of PS have been described (Table 1). ${ }^{3-5,7,13-15,18,20,22,33,38-59}$ In most patients, there is no identifiable cause.

Previous gluteal trauma can cause sciatica-like pain. ${ }^{22,33}$ This is probably the most common cause of PS. ${ }^{13,22,33}$ Certain anatomic variants, such as double piriformis and course variants of the sciatic nerve, posterior cutaneous femoral nerve, inferior gluteal nerve, and superior gluteal nerve ${ }^{4,5,7,14,15,26,27,40,41,60,61}$ can predispose to PS. ${ }^{7,26,34,44}$

The presence of PS is frequently overlooked; the differential diagnosis is presented in Table 2.3,4,7,9, $14,18,41,45,51,62-67$

\section{Clinical evaluation}

Clinical presentation

Three specific conditions may contribute to PS: 1) myofascial referred pain from trigger points in the PM; 2) adjacent muscles, nerve and vascular entrapment by the $\mathrm{PM}$ at the greater sciatic foramen; and 3) dysfunction of the sacroiliac joint. ${ }^{9,63,64}$

Myofascial pain syndrome in the PM is well recognized. ${ }^{7,20,38,39,50,64,68,69}$ Gluteal pain is reported to be observed in $97.9 \%$ of cases ${ }^{70}$ pain (and paresthesias) in the back, groin, perineum, buttocks, hip, back of the thigh $(81.9 \%),{ }^{70}$ calf $(59 \%),{ }^{70}$ foot, in the rectum (during defecation), and in the area of the coccyx. Low back pain is reported to be observed in $18.1 \%$ of cases. ${ }^{43,70}$ Some authors have suspected that contraction of the PM is an often overlooked cause of coccygodynia. ${ }^{13,24,41}$ Swelling in the affected leg and disturbances of sexual function are observed (dyspareunia in women, 13-100\%, ${ }^{71}$ and disturbances of potency in men are very often present as accompanying symptoms). ${ }^{4,7,71}$ Intense pain will occur when the patient sits or squats $(39-95 \%){ }^{71}$ 
A

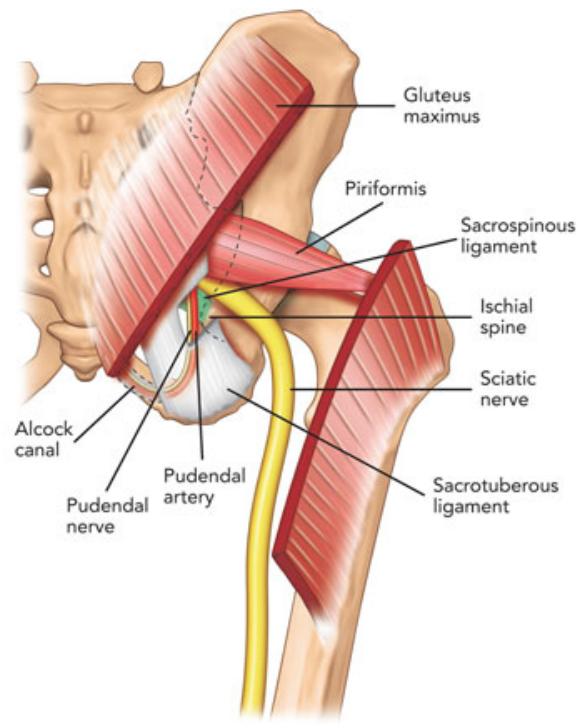

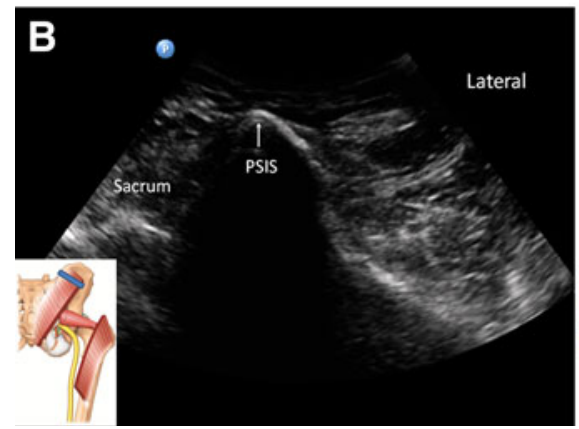
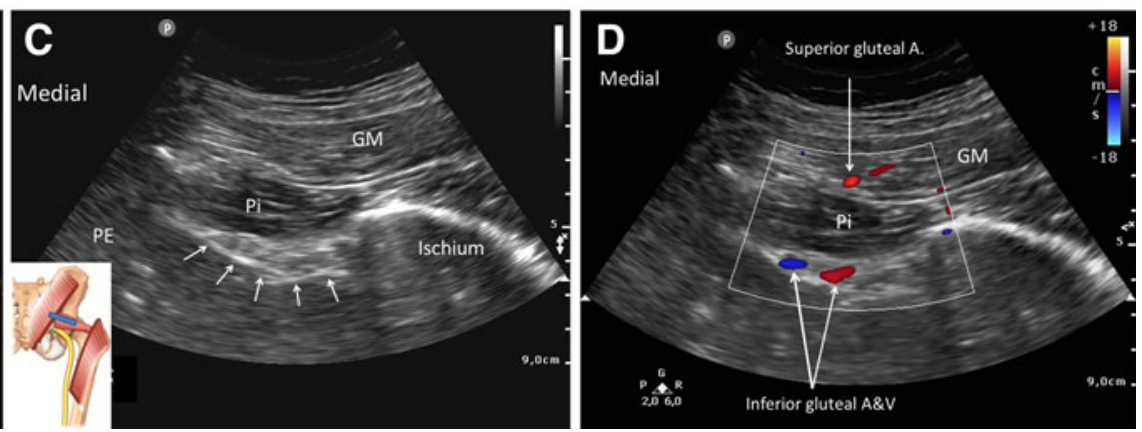

Fig. 3 Images reproduced with permission from Ultrasound for Regional Anesthesia, Toronto Western Hospital, Toronto, Canada ${ }^{28}$ (www.usra.ca). (A) Posterior view of the pelvis showing the piriformis muscle and surrounding structures. The gluteus maximus muscle has been transected to show the deeper structures. It should be pointed out that the sciatic nerve typically emerges caudal to the piriformis muscle in the greater sciatic notch. (B) Ultrasonography of the ilium cephalad to the greater sciatic notch. The position of the ultrasound probe (dark rectangle) is indicated in the insert. The ilium appears as a hyperechoic line. PSIS = posterior superior iliac spine. (C)

Table 1 Etiology of piriformis syndrome

- Gluteal trauma in the sacroiliac or gluteal areas (possibly several years previously) ${ }^{13,22,33}$

- Predisposing anatomic variants $4,5,7,14,15,40,41$

- Myofascial trigger points ${ }^{7,20,38,39,42}$

- Hypertrophy and spasm of the piriformis muscle $e^{14,18,43-45}$

- Secondary to laminectomy ${ }^{13,38,39,43,46-50}$

- Abscess, ${ }^{51}$ hematoma, ${ }^{52,53}$ myositis,${ }^{54}$ bursitis of the piriformis muscle ${ }^{55}$ neoplasms in the area of the infrapiriform foramen, ${ }^{56}$ colorectal carcinoma, ${ }^{57}$ neurinoma of the sciatic nerve, ${ }^{18}$ episacroiliac lipoma ${ }^{50}$

- Intragluteal injection ${ }^{58}$

- Femoral nailing ${ }^{18}$

- Myositis ossificans of the piriformis muscle 3,59

- Klippel-Trénaunay syndrome ${ }^{18}$
Ultrasound of the greater sciatic notch, with the position of the ultrasound probe indicated in the insert (dark rectangle). The sciatic nerve is seen as a structure deep to the piriformis muscle, indicated by the arrows. $\mathrm{GM}=$ gluteus maximus muscle; $\mathrm{PE}=$ peritoneum; $\mathrm{Pi}=$ piriformis muscle. (D) Ultrasonography of the sciatic notch as in $\mathrm{C}$, with Doppler imaging. The inferior gluteal artery is seen adjacent to the sciatic nerve, and the superior gluteal artery is located between the gluteus maximus (GM) and piriformis muscle ( $\mathrm{Pi}) . \mathrm{A}=$ artery; $\mathrm{V}=$ vein

Table 2 Differential diagnosis of piriformis syndrome

- Dysfunction, lesion, and inflammation of sacroiliac joint ${ }^{3,7,9,63,64}$

- Pseudoaneurysm in the inferior gluteal artery following gynecologic surgery, ${ }^{4,65}$

- Thrombosis of the iliac vein ${ }^{18,51,65}$

- Painful vascular compression syndrome of the sciatic nerve, caused by gluteal varicosities ${ }^{6}$

- Herniated intervertebral disc ${ }^{67}$

- Post-laminectomy syndrome or coccygodinia ${ }^{18,41}$

- Pseudoradicular S1 syndrome $\mathrm{e}^{45}$

- Posterior facet syndrome at L4-5 or L5-S16 ${ }^{3}$

- Unrecognized pelvic fractures ${ }^{14}$

- Lumbar osteochondrosis ${ }^{7,62}$

- Undiagnosed renal stones ${ }^{14}$ 
Nevertheless, true neurologic findings are not usually present in PS, and sensory deficits may be completely absent. ${ }^{3,5,14,38,39,64}$ There is no gold standard in diagnosing PS. The physical examination may reveal several of the following well-described signs. ${ }^{13,70}$ External palpation of the piriformis line can be used to elicit trigger-point tenderness through a relaxed gluteus maximus muscle. The patient is placed in the Sims position. The piriformis line overlies the superior border of the PM and extends from immediately above the greater trochanter to the cephalic border of the greater sciatic foramen at the sacrum. The line is divided into equal thirds. The fully rendered thumb presses on the point of maximum trigger-point tenderness, which is usually found just lateral to the junction of the middle and last thirds of the line. A positive test is reported to be observed in $59-92 \%$ of the patients. ${ }^{13,70,71}$ The piriformis sign, (which presents as tonic external rotation of the affected lower extremity) is reported to be observed in $38.5 \%$ of the patients. ${ }^{13}$ The medial end of the PM should be palpated within the pelvis by rectal or vaginal examination (this test is positive in almost $100 \%$ of the patients). ${ }^{7,13,41,72,73}$ Rectal or pelvic examination may reveal a tender palpable sausage-shaped mass along the lateral pelvic wall. Freiberg's sign ${ }^{13,14,19,67}$ involves pain on passive forced internal rotation of the hip in the supine position, thought to result from passive stretching of the $\mathrm{PM}$ and pressure on the sciatic nerve at the sacrospinous ligament. This test is positive in $56.2 \%$ of the patients (32$63 \%) .{ }^{70,71}$ Pace's sign ${ }^{13,38,39}$ consists of pain and weakness on resisted abduction and external rotation of the thigh in a sitting position. A positive test is reported to occur in $46.5 \%$ of the patients $(30-74 \%) .^{70,71}$ Lasègue's sign ${ }^{74}$ involves pain on the affected side on voluntary adduction, flexion, and internal rotation. Beatty's maneuver ${ }^{1,35}$ is an active test that involves elevation of the flexed leg on the painful side while the patient lies on the asymptomatic side. Abducting the thigh to raise the knee off the table elicits deep buttock pain in patients with PS but back and leg pain in those with lumbar disk disease. The Hughes test $^{75}$ (external isometric rotation of the affected lower extremity following maximal internal rotation) may also be positive in PS. Gluteal atrophy may be present ${ }^{13,33,38,45}$ as well as shortening of the limb on the affected side. ${ }^{7,45,72}$ Sacroiliac tenderness is reported to be observed in $38.5 \%$ of the patients. ${ }^{13}$

\section{Electrophysiological tests}

The role of unprovoked electrophysiological tests (in an anatomical position) is minimal. Nevertheless, the diagnostic value of such tests can be improved by stressing the muscle in flexion, adduction, and internal rotation (the FAIR test). ${ }^{14,15,19,70,76,77}$ The test compares posterior tibial and peroneal $\mathrm{H}$ reflexes elicited in the anatomic position with $\mathrm{H}$ reflexes obtained in flexion, adduction, and internal rotation [normal mean (SD) prolongation: 0.01 (0.62) msec]. A prolongation of $1.86 \mathrm{msec}$ in the FAIR test is an electrophysiological criterion for diagnosing PS. ${ }^{14,78}$ The test correlates well with estimates of pain on a visual analogue scale. ${ }^{14,15,19,70,76,77}$ Somatosensory-evoked cortical potentials are also reported to objectify sensory abnormalities of innervation. ${ }^{14,79}$

Imaging modalities

Plain pelvic radiography can identify calcification of the PM or its tendon only in exceptional circumstances. ${ }^{14,42}$ Involvement of the PM in sciatic neuropathy has been supported by evidence from computed tomography (CT), magnetic resonance imaging (MRI), ${ }^{62,68,80-84}$ scintigraphy, ${ }^{85}$ and ultrasound. ${ }^{36}$ Even so, if PS is suspected, a CT examination of the pelvis should certainly be conducted in order to detect side-to-side differences in the PM or other causes of the narrowing of the infrapiriform foramen. ${ }^{26,86,87}$ If uncertainties remain, an MRI examination of the sciatic nerve and its vicinity - particularly with regard to structural changes in the PM - is indicated. ${ }^{88}$ When the newly introduced neuroradiological technique of magnetic resonance neurography has been used alongside established imaging methods, such as MRI, for evaluating unexplained chronic sciatica, it has led to the identification of various changes relating to the PM and sciatic nerve which have been further shown with surgical exploration. ${ }^{26}$

Diagnostic injection with local anesthetics and steroids

Although PM injection has not been compared with other diagnostic tests, it is a widely used method of establishing the diagnosis after initial evaluation. . $^{13,38,39}$

\section{Management of PS}

\section{General}

Piriformis syndrome causing sciatica usually responds to conservative treatments, including physical therapy, lifestyle modification, pharmacological agents (non-steroidal antiinflammatory agents, muscle relaxants, and neuropathic pain medication), ${ }^{89}$ and psychotherapy. When patients fail to respond to simple conservative therapy, interventional modalities are considered. In rare circumstances, surgical release of the PM has been described for difficult cases of PS. There is a paucity of controlled trials critically examining the effectiveness of the noninvasive management modalities. Notwithstanding the lack of critical evaluation, the use of 
physical therapy methods are well supported in the literature. ${ }^{4,5,7,19-21,40,41,43,64,73,90}$ In general, physical therapy is performed only as part of multimodal therapy. Since PM injection is the main reason for the referral of this group of patients to an anesthesiologist/pain specialist, most of the discussion will focus on the technique.

\section{Piriformis muscle injection}

Piriformis muscle injection is usually offered to patients as part of multimodal therapy. The muscle can be targeted by a landmark-based technique, with or without the assistance of electrophysiological stimulation or image-guided techniques.

\section{Limitation of the current techniques}

Given the proximity of the PM to the pelvic cavity, sciatic nerve, and inferior gluteal artery (Figs. 1, 3A, 3D), landmark-based infiltration is not recommended.

Frequently, the landmark-based technique is accompanied with an electrophysiological stimulation method, such as the use of a nerve stimulator ${ }^{47,91}$ or electromyography; ${ }^{90}$ however, there are limitations with localization methods that use electrophysiological techniques. The premise in these techniques is that the close proximity of the needle to the muscle or nerve will reliably produce a brisk motor unit action potential or muscle contraction. Although this concept has not been validated for the electromyography-guided technique, the needle-to-nerve proximity relationship in nerve stimulation has been examined. ${ }^{92}$ Several studies using in vivo models have shown that the minimum stimulating current may not reliably reflect the distance of the needle tip from the nerve. ${ }^{93-96}$ Furthermore, the nerve stimulation technique cannot reliably differentiate whether the needle tip is within the muscle or lying in a plane between muscles (an important consideration when botulinum toxin is being injected). Both electrophysiological approaches neither allow direct visualization of the muscle nor ensure accurate positioning of the needle within the PM. ${ }^{97}$

Localization of the PM using the fluoroscopy-assisted contrast injection technique has also been examined. A cadaver study showed that the accuracy of this method was only $30 \%$, with most of the needle tip being positioned in the gluteus maximus muscle. ${ }^{98}$ This is not surprising given the fact that the fluoroscopy technique does not allow direct visualization of the soft tissue. Ultrasound and computer tomography (CT) have the advantage of allowing direct visualization of the PM. The reliability of the ultrasoundguided method has been confirmed in a cadaver study. ${ }^{98}$ Compared with a CT-guided technique, ultrasound is much more affordable and accessible. The ultrasound-guided technique also offers the additional advantages of avoiding radiation exposure and allowing real-time injection. ${ }^{97}$ In the experience of one of the present authors (P.P.), it is not uncommon for the patient to react when the practitioner injects the medication into the muscle. The pressure sensation on injection may elicit gluteus muscle contraction, which can displace the needle tip from the PM. This is particularly the case if the patient has developed piriformis atrophy with repeated injections of botulinum toxin. Real-time surveillance of the spread of the injectate can ensure that the needle is positioned within the muscle through the injection procedure. Because of the emerging popularity of the ultrasound-guided technique, details will be described below.

\section{Ultrasound-guided injection}

The accuracy of needle placement with ultrasound was recently validated in a cadaver study, suggesting an accuracy of $95 \% .^{98}$ There have been many reports of ultrasound-guided PM injection that describe similar techniques with minor variation..$^{36,80,98-100}$ The technique described below is the author's preferred technique. ${ }^{28}$

\section{Sonoanatomy $y^{97,100}$}

The key for locating the PM is the greater sciatic notch (Fig. 3A). The patient is placed in the prone position, and the ultrasound probe is placed just lateral to the posterior superior iliac spine (PSIS), revealing a hyperechoic bone shadow from the ilium (Fig. 3B). The ultrasound probe is then moved in the caudal direction toward the sciatic notch. At this level, the hyperechoic shadow of the bone will disappear from the medial aspect and two muscle layers will be visible - the gluteus maximus and the piriformis. The PM muscle can be better visualized by rotating the hip externally and internally with the knee flexed. This movement allows gliding of the PM in real time and helps the practitioner distinguish the PM from the gluteus muscle (Fig. 3C). The ultrasound scan should also show the presence of the sciatic nerve, inferior gluteal artery, and pelvic cavity, which are deep to the PM muscle (Figs. 3C, 3D).

\section{Injection technique}

The needle is inserted from medial to lateral using an inplane technique. Due to anatomic anomalies of the sciatic nerve within and below the PM, a practitioner with limited experience with ultrasound-guided injection is advised to perform the needle insertion with the nerve stimulator to prevent unintentional injection in the vicinity of the sciatic nerve. The stimulating current is usually set at $1 \mathrm{~mA}$. Either 
a 3.5 -in $22 \mathrm{G}$ spinal needle or an $80-\mathrm{mm}$ insulated needle is usually sufficient, but a longer needle is required for patients with a high body mass index. A very small amount of normal saline $(<0.5 \mathrm{~mL})$ is injected to confirm the intramuscular location of the needle (hydrolocation). The author usually chooses a small volume $(1-1.5 \mathrm{~mL})$ of injectate, whether it is botulinum toxin or a mixture of local anesthetic with steroid.

\section{Injection solution}

Mixing the local anesthetic solution with $20-40 \mathrm{mg}$ of a long-acting corticosteroid (e.g., long-acting methylprednisolone) is also recommended. ${ }^{101}$ Experience shows that long-acting local anesthetics do not provide any substantial advantages over short-acting agents. ${ }^{7,13,91}$

\section{Response to injections}

The response to injections can be immediate but may be of short duration. Recent reports have focused on botulinum toxin injections.

Botulinum toxin injections in PS $^{14,21,29,35,48,84,87,90,102-104}$

Botulinum toxin type $\mathrm{A}$ is one of seven immunologically distinct serotypes (A-G) of neurotoxin produced by Clostridium botulinum. Botulinum toxin type A can be administered with fluoroscopic, electromyelographic, CT, or MRI guidance. The recommended dose of botulinum toxin type A in PS is usually 100-200 units diluted in small volumes (1-1.5 mL) of normal saline. . $^{214,21,35,102}$

In summary, the indications, techniques, dosages, and monitoring vary significantly. This variability limits any comparison of studies and treatment groups. There is a lack of double-blind randomized controlled trials. More controlled studies are needed in order to determine the number of nerve blocks required in chronic pain therapy and to establish selection criteria for patients who are suitable for nerve blocks in pain therapy. The efficacy of nerve blocks depends on the stage of development of chronic pain.

\section{Surgical treatment}

Surgical intervention should be considered only when nonsurgical treatment has failed and the symptoms are becoming intractable and disabling, as the outcome is often disappointing. There is a lack of literature on surgical treatment for PS.

Classic indications for surgical treatment include abscess, neoplasms, hematoma, ${ }^{5,22,33,45,46,49}$ and painful vascular compression of the sciatic nerve caused by gluteal varicosities, etc. ${ }^{66}$ Since the introduction of botulinum toxin therapy, however, surgical interventions have rarely been necessary in patients with PS. The technical details of surgical treatment are beyond the scope of this review.

\section{Conclusions}

Piriformis syndrome continues to be a controversial diagnosis for sciatic pain. Given the fact that nerves and blood vessels accompany the PM, contracture of the latter can have widespread effects. Clinically, PS presents itself with pain (and paresthesias) in the buttocks, hips, and lower limbs. Electrophysiological testing and nerve blocks play important roles when the diagnosis is uncertain. Clinicians should be aware that many etiological factors are involved, which may be possible to modify or treat. Most patients respond to conservative measures, including nerve blocks, whereas surgical treatment is seldom necessary and often disappointing. Anesthesiologists are commonly involved in the management of PS due to their expertise in pain management and in carrying out nerve blocks. Injections of local anesthetics, steroids, and botulinum toxin into the PM muscle can serve both diagnostic and therapeutic purposes. The practitioner should be familiar with variations in the anatomy and the limitations of landmark-based techniques. An ultrasoundguided injection technique has recently been described, which offers improved accuracy in the nerve blockade. This technique has been shown to have both diagnostic and therapeutic value in the treatment of PS. Optimizing the therapeutic approach requires an interdisciplinary evaluation and treatment.

Sources of funding None. No financial sources were received to support this work.

Conflict of interest None declared. None of the authors have any association with pharmaceutical or medical manufacturing companies; none are consultants of any company. Dr. Philip Peng received equipment support from SonoSite Canada. He is a faculty member of Ultrasound for Regional Anesthesia (USRA) and publisher of the Philip Peng Educational Series.

\section{References}

1. Beatty RA. The piriformis muscle syndrome: a simple diagnostic maneuver. Neurosurgery 1994; 34: 512-4.

2. Fanucci E, Masala S, Sodani G, et al. CT-guided injection of botulinic toxin for percutaneous therapy of piriformis muscle syndrome with preliminary MRI results about denervative process. Eur Radiol 2001; 11: 2543-8.

3. Foster MR. Piriformis syndrome. Orthopedics 2002; 25: 821-5. 
4. Papadopoulos EC, Khan SN. Piriformis syndrome and low back pain: a new classification and review of the literature. Orthop Clin North Am 2004; 35: 65-71.

5. Parziale JR, Hudgins TH, Fischman LM. The piriformis syndrome. Am J Orthop (Belle Mead NJ) 1996; 25: 819-23.

6. Silver JK, Leadbetter WB. Piriformis syndrome: assessment of current practice and literature review. Orthopedics 1998; 21: 1133-5.

7. Travell JG, Simons DG. Myofascial Pain and Dysfunction: the Trigger Point Manual - the Lower Extremities - Volume 2. Baltimore: Lippincott Williams \& Wilkins; 1992. p. 186-214.

8. Hollinshead WH. Buttock, hip joint and thigh. In: Hollinshead WH. Anatomy for Surgeons 3rd ed. - The Back and Limbs. NY: Harper and Row; 1982: 666-8, 702.

9. Retzlaff EW, Berry AH, Haight AS, et al. The piriformis muscle syndrome. J Am Osteopath Assoc 1974; 73: 799-807.

10. McCrory $P$, Bell $S$. Nerve entrapment syndromes as a cause of pain in the hip, groin and buttock. Sports Med 1999; 27: 261-74.

11. Yeoman $W$. The relation of arthritis of the sacro-iliac joint to sciatica, with an analysis of 100 cases. Lancet 1928; 212: 1119-23.

12. Mixter WJ, Barr JS. Ruptures of the intervertebral disc with involvement of the spinal canal. N Engl J Med 1934; 211: 210-5.

13. Durrani Z, Winnie AP. Piriformis muscle syndrome: an underdiagnosed cause of sciatica. J Pain and Symptom Manage 1991; 6: 374-9.

14. Reichel $G$. Treatment of piriformis syndrome with botulinum toxin. Pain Headache 2003; 14: 140-58.

15. Huber HM. The piriformis syndrome - a possible cause of sciatica (German). Schweiz Rundsch Med Prax 1990; 79: 235-6.

16. Pfeifer T, Fitz WF. The piriformis syndrome (German). Z Orthop Ihre Grenzgeb 1989; 127: 691-4.

17. Hopayian $K$. Sciatica in the community - not always disc herniation. Int J Clin Pract 1999; 53: 197-8.

18. Reichel G, Gaerisch F Jr. Piriformis syndrome. A contribution to the differential diagnosis of lumbago and coccygodynia (German). Zentralbl Neurochir 1988; 49: 178-84.

19. Fishman LM, Dombi GW, Michaelsen C, et al. Piriformis syndrome: diagnosis, treatment, and outcome - a 10-year study. Arch Phys Med Rehabil 2002; 83: 295-301.

20. Hallin RP. Sciatic pain and the piriformis muscle. Postgrad Med 1983; 74: 69-72.

21. Fishman LM, Anderson C, Rosner B. Botox and physical therapy in the treatment of piriformis syndrome. Am J Phys Med Rehabil 2002; 81: 936-42.

22. Benson ER, Schutzer SF. Posttraumatic piriformis syndrome: diagnosis and results of operative treatment. J Bone Joint Surg Am 1999; 81: 941-9.

23. Beaton LE, Anson BJ. The sciatic nerve and the piriformis muscle: their interrelation a possible cause of coccygodynia. J Bone Joint Surg Am 1938; 20: 686-8.

24. Beaton LE, Anson BJ. The relation of the sciatic nerve and of its subdivisions to the piriformis muscle. Anat Rec 1937; 70: 1-5.

25. Uluutku MH, Kurtoglu Z. Variations of nerves located in deep gluteal region. Okajimas Folia Anat Jpn 1999; 76: 273-6.

26. Cassidy L, Walters A, Bubb K, Shoja MM, Tubbs RS, Loukas M. Piriformis syndrome: implications of anatomical variations, diagnostic techniques, and treatment options. Surg Radiol Anat 2012; 34: 479-86.

27. Tillmann B. Variations in the pathway of the inferior gluteal nerve (author's transl) (German). Anat Anz 1979; 145: 293-302.

28. Peng PH. Piriformis syndrome. In: Peng PH, editor. Ultrasound for Pain Medicine Intervention: A Practical Guide. Volume 2. Pelvic Pain. Philip Peng Educational Series. 1st ed. iBook, CA: Apple Inc.; 2013 .

29. Childers MK. Use of Botulinum Toxin Type A in Pain Management. Columbia, MO: Academic Information Systems/ Austin, TX: Greenleaf Book Group; 2002.
30. Porta M. A comparative trial of botulinum toxin type A and methylprednisolone for the treatment of myofascial pain syndrome and pain from chronic muscle spasm. Pain 2000; 85: 101-5.

31. Meknas K, Christensen A, Johansen $O$. The internal obturator muscle may cause sciatic pain. Pain 2003; 104: 375-80.

32. Puranen J, Orava S. The hamstring syndrome - a new gluteal sciatica. Ann Chir Gynaecol 1991; 80: 212-4.

33. Robinson DR. Piriformis syndrome in relation to sciatic pain. Am J Surg 1947; 73: 355-8.

34. Pecina M. Contribution to the etiological explanation of the piriformis syndrome. Acta Anat (Basel) 1979; 105: 181-7.

35. Kirschner JS, Foye PM, Cole JL. Piriformis syndrome, diagnosis and treatment. Muscle Nerve 2009; 40: 10-8.

36. Smith J, Hurdle MF, Locketz AJ, Wisniewski SJ. Ultrasoundguided piriformis injection: technique description and verification. Arch Phys Med Rehabil 2006; 87: 1664-7.

37. Goldner JL. Piriformis compression causing low back and lower extremity pain. Am J Orthop (Belle Mead NJ) 1997; 26: 316, 318.

38. Pace JB. Commonly overlooked pain syndromes responsive to simple therapy. Postgrad Med 1975; 58: 107-13.

39. Pace JB, Nagle D. Piriform syndrome. West J Med 1976; 124 : 435-9.

40. Douglas $S$. Sciatic pain and piriformis syndrome. Nurse Pract 1997; 22: 166-8.

41. Thiele GH. Coccygodynia and pain in the superior gluteal region and down the back of the thigh: causation by tonic spasm of the levator ani, coccygeus and piriformis muscles and relief by massage of these muscles. JAMA 1937; 109: 1271-5.

42. Stark P, Hildebrandt-Stark HE. Calcific tendinitis of the piriform muscle. Rofo 1983; 138: 111-2.

43. Benzon HT, Katz JA, Benzon HA, Iqbal MS. Piriformis syndrome: anatomic considerations, a new injection technique, and a review of the literature. Anesthesiology 2003; 98: 1442-8.

44. Chen WS, Wan YL. Sciatica caused by piriformis muscle syndrome: report of two cases. J Formos Med Assoc 1992; 91: 647-50.

45. Rodrigue T, Hardy RW. Diagnosis and treatment of piriformis syndrome. Neurosurg Clin N Am 2001; 12: 311-9.

46. Filler AG, Haynes BA, Jordan SE, et al. Sciatica of nondisc origin and piriformis syndrome: diagnosis by magnetic resonance neurography and interventional magnetic resonance imaging with outcome study of resulting treatment. J Neurosurg Spine 2005; 2: 99-115.

47. Hanania $M$. New technique for piriformis muscle injection using a nerve stimulator. Reg Anesth 1997; 22: 200-2.

48. Hanania $M$, Kitain E. Perisciatic injection of steroid for the treatment of sciatica due to piriformis syndrome. Reg Anesth Pain Med 1998; 23: 223-8.

49. Mizugushi T. Division of the piriformis muscle for the treatment of sciatica. Postlaminectomy syndrome and osteoarthritis of the spine. Arch Surg 1976; 111: 719-22.

50. Pace JB, Henning $C$. Episacroiliac lipoma. Am Fam Physician 1972; 6: 70-3.

51. Arai Y, Kawakami T, Soga H, Okada Y. Psoas abscess associated with iliac vein thrombosis and piriformis and gluteal abscesses. Int J Urol 1999; 6: 257-9.

52. Katati MJ, Vilchez R, Pinar L, et al. Haematoma of the piriformis muscle simulating a giant presacral tumour: unusual case of lumbosacral radiculopathy. Acta Neurochir (Wien) 1998; 140: 403-4.

53. Ku A, Kern H, Lachman E, Nagler $W$. Sciatic nerve impingement from piriformis hematoma due to prolonged labor. Muscle Nerve 1995; 18: 789-90.

54. Chusid MJ, Hill WC, Bevan JA, Sty JR. Proteus pyomyositis of the piriformis muscle in a swimmer. Clin Infect Dis 1998; 26: 194-5. 
55. Peh WC, Reinus WR. Piriformis bursitis causing sciatic neuropathy. Skeletal Radiol 1995; 244: 474-6.

56. Hockel M. Laterally extended endopelvic resection: surgical treatment of infrailiac pelvic wall recurrences of gynecologic malignancies. Am J Obstet Gynecol 1999; 180: 306-12.

57. LaBan MM, Meerschaert JR, Taylor RS. Electromyographic evidence of inferior gluteal nerve compromise: an early representation of recurrent colorectal carcinoma. Arch Phys Med Rehabil 1982; 63: 33-5.

58. Obach J, Aragones JM, Ruano D. The infrapiriformis foramen syndrome resulting from intragluteal injection. J Neurol Sci 1983; 58: 135-42.

59. Beauchesne RP, Schutzer SF. Myositis ossificans of the piriformis muscle: an unusual cause of piriformis syndrome. A case report. J Bone Joint Surg Am 1997; 79: 906-10.

60. Rask MR. Superior gluteal nerve entrapment syndrome. Muscle Nerve 1980; 3: 304-7.

61. Sayson SC, Ducey JP, Maybrey JB, Wesley RL, Vermilion D. Sciatic entrapment neuropathy associated with an anomalous piriformis muscle. Pain 1994; 59: 149-52.

62. Kipervas IP, Ivanov LA, Urikh EA, Pakhomov SK. Clinicoelectromyographic characteristics of piriform muscle syndromes (Russian). Zh Nevropatol Psikhiatr Im S S Korsakova 1976; 76: 1289-92.

63. Kirkaldy-Willis WH, Hill RJ. A more precise diagnosis for lowback pain. Spine (Phila Pa 1976) 1979; 4: 102-9.

64. Steiner $C$, Staubs $C$, Ganon $M$, Buhlinger $C$. Piriformis syndrome: pathogenesis, diagnosis, and treatment. J Am Osteopath Assoc 1987; 87: 318-23.

65. Papadopoulos SM, McGillicuddy JE, Albers JW. Unusual cause of "piriformis muscle syndrome". Arch Neurol 1990; 47: 1144-6.

66. Bendszus M, Rieckmann P, Perez J, Koltzenburg M, Reiners K, Solymosi L. Painful vascular compression syndrome of the sciatic nerve caused by gluteal varicosities. Neurology 2003; 61: 985-7.

67. Freiberg $A H$. Sciatic pain and its relief by operations on muscle and fascia. Arch Surg 1937; 34: 337-50.

68. Stewart JD. The piriformis syndrome is overdiagnosed. Muscle Nerve 2003; 28: 644-6.

69. Wynant GM. Chronic pain syndromes and treatment. III. The piriformis syndrome. Canad Anaesth Soc J 1979; 26: 305-8.

70. Blaser-Sziede R. Piriformissyndrom — kritische beurteilung der literatur und diskussion der klinischen zusammenhänge (German). Man Ther 2006; 10: 159-69.

71. Hopayian K, Song F, Riera R, Sambandan S. The clinical features of the piriformis syndrome: a systematic review. Eur Spine J 2010; 19: 2095-109.

72. TePoorten BA. The piriformis muscle. J Am Osteopath Assoc 1969; 69: 150-60

73. Barton PM. Piriformis syndrome: a rational approach to management. Pain 1991; 47: 345-52.

74. Fishman SM, Caneris OA, Bandmann TB, Audette JF, Borsook D. Injection of the piriformis muscle by fluoroscopic and electromyographic guidance. Reg Anesth Pain Med 1998; 23: 554-9.

75. Hughes SS, Goldstein MN, Hicks DG, Pellegrini VD Jr. Extrapelvic compression of the sciatic nerve. An unusual cause of pain about the hip: report of five cases. J Bone Joint Surg Am 1992; 74: 1553-9.

76. Dumitru D, Nelson MR. Posterior femoral cutaneous nerve conduction. Arch Phys Med Rehabil 1990; 71: 979-82.

77. Spinner RJ, Thomas NM, Kline DG. Failure of surgical decompression for a presumed case of piriformis syndrome. Case report. J Neurosurg 2001; 94: 652-4.

78. Fishman LM, Zybert PA. Electrophysiologic evidence of piriformis syndrome. Arch Phys Med Rehabil 1992; 73: 35964.
79. Nainzadeh $N$, Lane ME. Somatosensory evoked potentials following pudendal nerve stimulation as indicators of low sacral root involvement in a postlaminectomy patient. Arch Phys Med Rehabil 1987; 68: 170-2.

80. Broadhurst NA, Simmons DN, Bond MJ. Piriformis syndrome: correlation of muscle morphology with symptoms and signs. Arch Phys Med Rehabil 2004; 85: 2036-9.

81. Jankiewicz JJ, Hennrikus WL, Houkom JA. The appearance of the piriformis muscle syndrome in computed tomography and magnetic resonance imaging. A case report and review of the literature. Clin Orthop Relat Res 1991; 262: 205-9.

82. Lee EY, Margherita AJ, Gierada DS, Narra VR. MRI of piriformis syndrome. AJR Am Roentgenol 2004; 183: 63-4.

83. Rossi P, Cardinali P, Serrao M, Parisi L, Bianco F, De Bac S. Magnetic resonance imaging findings in piriformis syndrome: a case report. Arch Phys Med Rehabil 2001; 82: 519-21.

84. Yue SK. Morphological findings of asymmetrical and dystrophic psoas and piriformis muscles in chronic lower back pain during CT guided botulinum toxin injections (abstract). Reg Anesth Pain Med 1998; 23(3 Suppl): 104.

85. Karl RD Jr, Yedinak MA, Hartshorne MF, et al. Scintigraphic appearance of the piriformis muscle syndrome. Clin Nucl Med 1985; 10: 361-3.

86. Ueno K, Matsuzawa H, Inoue A. $67 \mathrm{Ga}$ imaging of gluteal muscle inflammation secondary to pyogenic sacroiliitis (PSI) (Japanese). Rinsho Hoshasen 1985; 30: 319-22.

87. Fanucci E, Masala S, Squillaci E, et al. Piriformis muscle syndrome: CT/MR findings in the percutaneous therapy with botulinic toxin. Radiol Med 2003; 105: 69-75.

88. Almanza MY, Poon-Chue A, Terk MR. Dual oblique MR method for imaging the sciatic nerve. J Comput Assist Tomogr 1999; 23: 138-40.

89. Dworkin RH, O'Connor AB, Bakonja M, et al. Pharmacologic management of neuropathic pain: evidence-based recommendations. Pain 2007; 132: 237-51.

90. Fishman LM, Konnoth C, Rozner B. Botulinum neurotoxin type $B$ and physical therapy in the treatment of piriformis syndrome: a dose-finding study. Am J Phys Med Rehabil 2004; 83: 42-50.

91. Jankovic D. Infiltration der triggerpunkte des M. piriformis ("piriformis syndrom"). In: Jankovic D (Ed.). Regionalblockaden \& Infiltrattionstherapie. Lehrbuch und Atlas, 4th ed. (German). Berlin: ABW-Verlag, 2008: 306-9.

92. Macfarlane AJ, Bhatia A, Brull R. Needle to nerve proximity: what do the animal studies tell us? Reg Anesth Pain Med 2011; 36: 290-302.

93. Rigaud M, Filip P, Lirk P, Fuchs A, Gemes G, Hogan $Q$. Guidance of block needle insertion by electrical nerve stimulation: a pilot study of the resulting distribution of injected solution in dogs. Anesthesiology 2008; 109: 473-8.

94. Chan VW, Brull R, McCartney CJ, Xu D, Abbas S, Shannon P. An ultrasonographic and histological study of intraneural injection and electrical stimulation in pigs. Anesth Analg 2007; 104: 1281-4.

95. Tsai TP, Vuckovic I, Dilberovic F, et al. Intensity of the stimulating current may not be a reliable indicator of intraneural needle placement. Reg Anesth Pain Med 2008; 33: 207-10.

96. Altermatt FR, Cummings TJ, Auten KM, Baldwin MF, Belknap SW, Reynolds $J D$. Ultrasonographic appearance of intraneural injections in the porcine model. Reg Anesth Pain Med 2010; 35: 203-6.

97. Peng $P, \quad$ Narouze $S$. Ultrasound-guided interventional procedures in pain medicine: a review of anatomy, sonoanatomy, and procedures: part I: nonaxial structures. Reg Anesth Pain Med 2009; 34: 458-74.

98. Finoff JT, Hurdle MF, Smith J. Accuracy of ultrasound-guided versus fluoroscopically guided contrast controlled piriformis injections. A cadaveric study. J Ultrasound Med 2008; 27: 1157-63. 
99. Huerto AP, Yeo SN, Ho KY. Piriformis muscle injection using ultrasonography and motor stimulation - report of a technique. Pain Physician 2007; 10: 687-90.

100. Peng PW, Tumber PS. Ultrasound-guided interventional procedures for patients with chronic pelvic pain - a description of techniques and review of literature. Pain Physician 2008; 11 : 215-24.

101. Johansson A, Hao J, Sjolund B. Local corticosteroid application blocks transmission in normal nociceptive C-fibres. Acta Anaesthesiol Scand 1990; 34: 335-8.
102. Yoon SJ, Ho J, Kang HY, et al. Low-dose botulinum toxin type A for the treatment of refractory piriformis syndrome. Pharmacotherapy 2007; 27: 657-65.

103. Childers MK, Wilson DJ, Gnatz SM, Conway RR, Sherman Ak. Botulinum toxin type A use in piriformis muscle syndrome: a pilot study. Am J Phys Med Rehabil 2002; 81: 751-9.

104. Lang AM. Botulinum toxin type B in piriformis syndrome. Am J Phys Med Rehabil 2004; 83: 198-202. 